\title{
Update on Hereditary Colorectal Cancer
}

\author{
FELIPE CARNEIRO DA SILVA ${ }^{1}$, PATRIK WERNHOFF ${ }^{2}$, \\ CONSTANTINO DOMINGUEZ-BARRERA ${ }^{3}$ and MEV DOMINGUEZ-VALENTIN ${ }^{4}$
}

${ }^{1}$ Laboratory of Experimental Oncology, Federal University of Piauí, Teresina, Brazil;

${ }^{2}$ Department of Experimental Medical Science, Unit of Muscle Biology,

Lund Transgenic Core Facility/Reproductive Immunology, Lund University, Lund, Sweden;

${ }^{3}$ Department of Preventive Medicine, Faculty of Medicine, National University of San Marcos, Lima, Peru;

${ }^{4}$ Deparment of Tumor Biology, Institute for Cancer Research, Oslo University Hospital, Oslo, Norway

\begin{abstract}
In the past two decades, significant advances have been made in our understanding of colorectal (CRC) tumors with DNA mismatch (MMR) repair deficiency. The knowledge from molecular and genetic alterations in a variety of clinical conditions has refined the disease terminology and classification. Hereditary non-polyposis colorectal cancer (HNPCC) encompasses a spectrum of conditions that have significant phenotypic overlapping that makes clinical diagnosis a challenging task. Distinguishing among the HNPCC disorders is clinically important, as the approach to surveillance for patients and their at-risk family members differs according to risks for colonic and extracolonic cancer associated with each syndrome. Prospective and next-generation studies will provide valuable clinical information regarding the natural history of disease that will help differentiate the Lynch syndrome mimics and guide diagnosis and management for heterogeneous conditions currently grouped under the category of familial $C R C$. The review is intended to present and discuss the molecular nature of various conditions related to MMR deficiency and discusses the tools and strategies that have been used in detecting these conditions.
\end{abstract}

We have entered a genomic era of cancer research which may lead to new possibilities of cancer treatment. Next-generation DNA sequencing has greatly improved the detection of DNA

This article is freely accessible online.

Correspondence to: Mev Dominguez-Valentin, Deparment of Tumor Biology, Institute for Cancer Research, Oslo University Hospital. E-mail: mev_dv@yahoo.com

Key Words: 4ereditary non-polyposis colorectal cancer, Lynch syndrome, Lynch-like syndrome, FCCTX, mismatch repair, review. variants in the genome of each individual and contributes to a personalized management of an individual's cancer (1).

Colorectal cancer (CRC) is the third most common cancer and the fourth most common cause of cancer death in the world (2). Heredity represents a major cause of CRC, with up to $30 \%$ of the cases estimated to develop due to genetic factors and about 5\% linked to inherited mutations in cancerpredisposing genes (3). Identifying these high-risk patients is a major issue because morbidity and mortality from CRC and extracolonic cancer in patients and their relatives can be reduced by early and intensive screening $(4,5)$.

Familial CRC was first described in 1966 by Lynch, who referred to type I for families with CRC only, and type II for families with cancer also including gynecological cancer (6). Later, the term hereditary non-polyposis colorectal cancer (HNPCC) was introduced to emphasize the lack of a polyposis phenotype. In 1984, the term 'Lynch syndrome' was proposed to describe this condition and has been most commonly used since then (7). Although the term HNPCC is often used interchangeably with Lynch syndrome, it is important to remember that HNPCC is a clinical diagnosis for patients and families that meet Amsterdam I or II criteria (AC), whereas diagnosis of Lynch syndrome requires presence of a genetically confirmed disease-predisposing mismatch repair $(\mathrm{MMR})$ mutation $(8,9)$.

In order to stratify families for genetic analysis, the AC were developed to permit the identification of MMR defects and their association within tumor spectrum $(10,11)$. The AC requires at least three affected family members in two or more generations, with one being a first-degree relative of the other two and at least one individual diagnosed before 50 years of age $(10,12)$. AC-I applies to families with three or more cases of CRC and AC-II also includes extracolonic tumors, i.e. endometrial cancer, cancer of the upper urinary tract and cancer of the small bowel $(10,12)$. The Bethesda 
guidelines included the tumor marker of microsatellite instability (MSI), and the revised Bethesda criteria specified all cancer known at the time to be associated with the syndrome $(11,13)$.

Among AC-positive families, disease-predisposing mutations in MMR genes characteristic of Lynch syndrome can be identified in $\sim 60 \%$, whereas $40 \%$ do not show MMR defects and are, accordingly, referred to as familial colorectal cancer type X (FCCTX) $(14,15)$. The term FCCTX was coined by Lindor and colleagues in 2005 to describe families that meet AC-I, but have MMR-proficient tumors. The polyp burden and risk factors of FCCTX have not been fully and independently characterized. Lynch-like syndrome describes cases where molecular testing demonstrates the presence of MSI with/without abnormal expression of MMR proteins on immunohistochemical (IHC) testing of tumors, without the presence of characteristic germline mutations seen in Lynch syndrome $(16,17)$ (Figure 1).

In this review, we discuss the recent knowledge on the molecular nature of familial CRC, and definitions of the various conditions related to MMR deficiency. The review aims to improve our understanding of hereditary CRC risk, pathogenesis and prevention.

\section{Lynch Syndrome}

Lynch syndrome is the most common inheritable type of CRC, accounting for $2 \%$ to $4 \%$ of $\mathrm{CRC}$, and has an estimated prevalence in the general population of one in 440 (18-20). Lynch syndrome increases the risk for CRC (lifetime risk $=70-80 \%$ ), and endometrial (50-60\%), stomach (13-19\%) and ovarian (9-14\%) cancer, and of the small intestine, biliary tract, and brain, as well as carcinoma of the ureters and renal pelvis (21). Nowadays, most patients with Lynch syndrome have been identified following investigation because of their family or personal history of multiple or early-onset cancer (4).

Lynch syndrome is caused by a defective MMR system due to the presence of germline defects in at least one of the MMR genes - mutL homolog 1 (MLH1), mutS homolog 2 (MSH2), mutS homolog 6 (MSH6) and postmeiotic segregation increased 2 (PMS2). An estimated $80-90 \%$ of Lynch syndrome is attributable to deleterious mutations in MLH1 and MSH2, with the remaining $10-20 \%$ due to mutations in MSH6 and PMS2. Moreover, up to 3\% of Lynch syndrome is due to mutations in the epithelial cell adhesion molecule (EPCAM), which is directly upstream of $M S H 2$. Deletions of the 3'-end of EPCAM result in epigenetic hypermethylation of the $M S H 2$ promoter, producing a phenotype very similar to Lynch syndrome (9). Recent studies have described large deletions encompassing EPCAM exons 5 to 9 and others, including a large deletion involving both EPCAM and MSH2 genes (22-26) (Figure 2). The cumulative incidence of any cancer at 70 years of age is $72 \%$ for $\mathrm{MLH1}$ and $\mathrm{MSH} 2$ mutation carriers but lower in MSH6 (52\%) and PMS2 (18\%) mutation carriers. MSH6 and PMS2 carriers developed no cancer before 40 years of age (4).

To date over 3,100 unique DNA variants across the MMR genes have been described in the International Society for Gastrointestinal Hereditary Tumors (InSIGHT) database (http://insight-group.org/variants/database/) and a recent clinical InSiGHT consensus classification identified $57 \%$ of the MMR variants as pathogenic or likely pathogenic (Class 5 and 4), 32\% as uncertain variants (Class 3), $4 \%$ as likely not pathogenic (Class 2) and $7 \%$ as not pathogenic (Class 1) (27).

\section{Lynch-like Syndrome}

The term Lynch-like syndrome, or suspected Lynch syndrome has been suggested to describe patients with tumors showing deficient DNA MMR expression, but no identified deleterious germline mutation in MMR genes (Figure 1). B-Raf protooncogene, serine/threonine kinase $(B R A F)$ V600E mutation or $M L H 1$ promoter hypermethylation have not been found in Lynch-like tumors, demonstrating that the deficiency of MLH1 expression is not due to BRAF mutation $(16,17)$. Lynch-like syndrome may account for up to $70 \%$ of cases in which Lynch syndrome is clinically suspected with a high MSI profile and absence of a MMR proteins (17).

From a clinical perspective, patients with Lynch-like syndrome present cancer at younger ages, similarly to those with Lynch syndrome (17). Buchanan et al. described family histories of Lynch-like syndrome patients with high incidence of metachronous and synchronous CRC and fulfillment of AC (28). On the other hand, Mas-Moya and colleagues identified significant differences between patients with Lynch-like syndrome and those with Lynch syndrome (29). The majority of those with Lynch-like syndrome had CRC in the right colon (93\%) when compared to those with Lynch syndrome (45\%). In this regard, out of all patients with left-sided or rectal adenocarcinoma, 96\% (23/24) demonstrated germline mutations (defined as Lynch syndrome) (29).

There are growing hypothesis regarding the pathogenesis of Lynch-like syndrome $(28,30,31)$. Some authors suggested that patients with Lynch-like syndrome could actually have Lynch syndrome but their germline mutations in MMR genes might not be detectable by current testing (28). Recently, Liu and colleagues identified a patient with family history of early-onset CRC carrying an unbalanced paracentric inversion spanning exon 2 to 6 of $M S H 2$ (30). In this regard, Rhees et al. found a significant proportion of patients with previously unexplained MSH2-type Lynch syndrome harboring an inversion from exon 1 to 7 in $\mathrm{MSH} 2$ gene (31). 


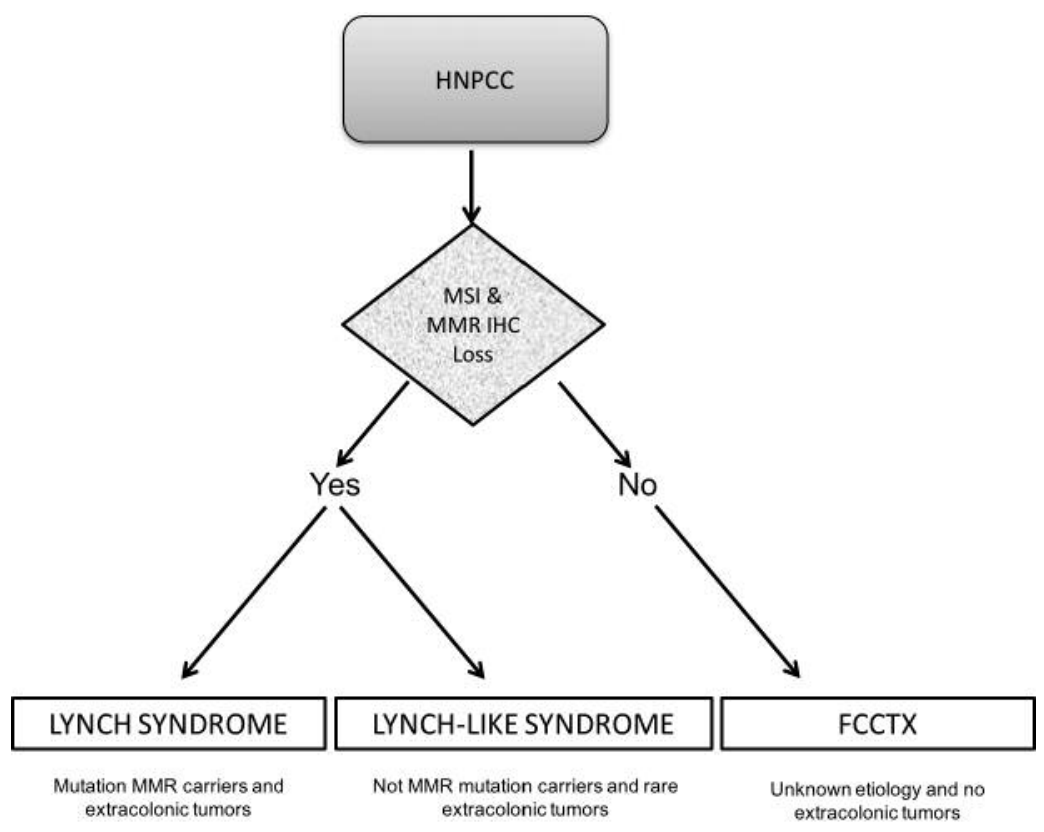

Figure 1. Hereditary non-polyposis colorectal cancer (HNPCC) as a familial colorectal cancer aggregation. At least three different entities based on immunohistochemistry (IHC) and microsatellite instability (MSI) analysis have been proposed, including Lynch syndrome, Lynch-like syndrome and familial colorectal cancer type X (FCCTX). MMR: Mismatch repair genes (MMR).

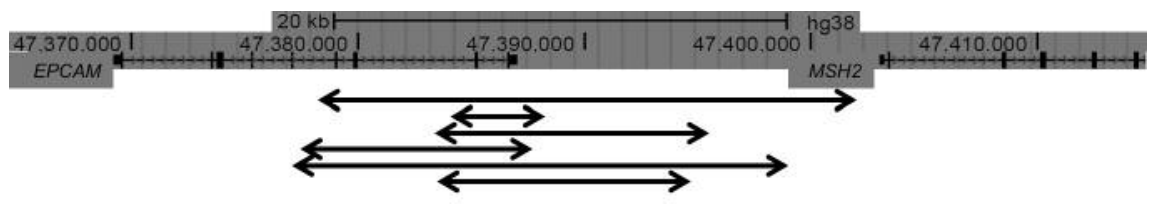

Figure 2. Genomic rearrangement upstream of the mutS homolog 2 (MSH2) gene. Black arrows show different reported deletions encompassing the last exons of the epithelial cell adhesion molecule (EPCAM) gene. Adapted from (22-26).

There are other mechanisms that inactivate DNA MMR genes which could result in tumors that resemble Lynch syndrome. For instance, around $60 \%$ of Lynch-like CRCs exhibit bi-allelic somatic inactivation of MMR genes within the tumor (32-34). A somatic mutation in one allele of MMR genes along with loss of heterozygosity of the other allele is the most common described pattern $(17,35)$. These somatic MMR gene mutations are likely sporadic events, suggesting that such tumors are most likely cancers with sporadic DNA MMR deficiency.

\section{Familial Colorectal Cancer Type X}

Families meeting AC-I for Lynch syndrome, but not carrying deleterious alterations in MMR genes, nor MSI, are defined as having FCCTX (36), however, some studies have also included AC-II with microsatellite stable (MSS) tumors (36-
40). CRCs in FCCTX families are diagnosed at a slightly older age compared to those with Lynch syndrome and the risk of extracolonic cancer is not more than that of the average-risk population (14).

The FCCTX subset is challenging, not least since the clinical presentation and the histopathological features mimic sporadic MMR-proficient tumors. The genetic causes are unknown but candidate genes include $e . g$. centromere protein $\mathrm{E}(C E N P E)$, kinesin family member 24 (KIF24), polypeptide $N$-acetylgalactosaminyltransferase 12 (GALNT12), zinc finger protein 367 (ZNF367), hyaluronan binding protein 4 $(H A B P 4)$, gamma-aminobutyric acid type $\mathrm{B}$ receptor subunit 2 (GABBR2) and bone morphogenetic protein 4 (BMP4). Differences in genomic and gene-expression profiles do exist, e.g. gain of chromosome 20q, global hypomethylation and up-regulation of the G-protein-coupled receptorsignaling pathway (40). 
Alterations in APC, WNT signaling pathway regulator $(A P C)$ and KRAS proto-oncogene, GTPase $(K R A S) /$ Raf-1 proto-oncogene, serine/threonine kinase (RAF1) signaling pathway have been described in FCCTX, resembling those in Lynch syndrome and sporadic CRC, respectively (41-43). In addition, it has been suggested that base-excision repair pathways and epigenetic events could be implicated in FCCTX pathogenesis $(41,42)$.

A subgroup of FCCTX tumors related to the $\mathrm{CpG}$ island methylator phenotype pathway have been characterized by simultaneous methylation of gene promoters resulting in transcriptional silencing, high MSI and BRAF mutations, as well as a subgroup arising through the chromosomal instability pathway, characterized by aneuploidy and $\mathrm{LOH}$, which is thought to be involved in most CRC (43).

The clinical phenotype of FCCTX substantially differs from that Lynch syndrome families, which includes fewer cases of CRC, higher age of CRC onset, more tumors of the left colon, and fewer extracolonic manifestations (43-46). According to Kravochuck and Church, families with FCCTX do not have a specific syndrome but may have one of several genotypes, including mutY DNA glycosylase (MUTYH)associated polyposis, nth-like DNA glycosylase 1 (NTHL1)associated polyposis, polymerase proofreading-associated polyposis, or serrated polyposis (35).

The overall risk of cancer is lower in FCCTX than in Lynch syndrome $(14,47)$, in which the lifetime CRC risk is estimated to be $50-80 \%$. Age at diagnosis of CRC differs, with a mean age of 48 years in Lynch syndrome and 60 years in FCCTX $(14,48-51)$. Synchronous and metachronous adenomatous polyps are more common in FCCTX than in Lynch syndrome (46). Further studies are required, however, since tumors arising within FCCTX families also appear to have a different pathological phenotype, with fewer tumorinfiltrating lymphocytes than those from families with Lynch syndrome (46).

Extended and in-depth analyses of the FCCTX tumor genome, methylome and proteome in well-defined tumor series could shed light on the basic mechanisms for potential application in refined diagnosis and targeted interventions (40).

\section{Recommendations for Surveillance}

Hereditary CRC syndromes provide a wealth of opportunities for highly targeted clinical management and prevention (52, 53). The key to prevention is early diagnosis through a comprehensive family history, followed by germline mutation testing if appropriate, and targeted surveillance and management for patients with mutations $(52,53)$.

For Lynch syndrome, initiating colonoscopy is recommended at age 20-25 years (or the age of 30 and 35 years in patients with MSH6 and PMS2 mutations, respectively) or 2-5 years prior to the earliest case of CRC, if it is diagnosed before the age of 25 years, and repeated every 1-2 years $(9,53)$. No specific upper limit is established and this should be based on the individual's health status (54, 55). Endometrial and ovarian cancer screening may be performed on a yearly basis from age 30-35 years with gynecological examination, pelvic ultrasound, cancer antigen 125 (CA125) analysis, and endometrial aspiration biopsy.

The American Society of Clinical Oncology endorsement panel concurs with the European society for medical oncology recommendations (55) and the National comprehensive Cancer Network guidelines (https://www.nccn.org/professionals/ physician_gls/f_guidelines.asp\#genetics_colon) for Lynch syndrome that prophylactic removal of the uterus and ovaries might be an option in female carriers from age 35 years and after childbearing is completed (56). Surveillance for other Lynch-associated cancers is recommended based on family history and may include upper endoscopy, and abdominal ultrasound with urine cytology from age 30-35 years at 1-2 year intervals. In Lynch syndrome, there is an increased risk of synchronous and metachronous CRC, with a risk of $16 \%$ of developing a second CRC after 10 years of follow-up $(54,55)$. Therefore, the need for intensive surveillance after surgery versus the option of an extended colectomy should be discussed at the time of CRC diagnosis, especially for young patients. Although some preclinical data suggest that MMR status may play a role as factor predictive of chemosensitivity, as well as prognosis and treatment, current evidence does not allow definitive recommendation on chemotherapy regimens to be made based on MSI status (54).

Surveillance programs in FCCTX are targeted at CRC and the mean age at onset of 60 years implies that surveillance colonoscopies are generally recommended with 3- to 5-year intervals, starting 5-10 years before the earliest age at onset in the family $(44,54)$. CRC surveillance in FCCTX families is very important. More efforts are needed to improve the identification of patients with familial CRC since a modestly increased risk of CRC has been described for these families $(14,54)$.

In terms of chemoprevention for CRC, there are reasonably compelling data supporting that aspirin is protective against CRC and some extracolonic tumors (57). Although current guidelines do not routinely recommend its use, recent data from the Colorectal Adenoma/Carcinoma Prevention Program (CAPP2) in a randomized, placebocontrolled trial showed a significant $60 \%$ reduction in the incidence of CRC and other Lynch syndrome-associated cancers among those using $600 \mathrm{mg}$ of aspirin per day for at least 2 years $(55,58)$.

Understanding the molecular genetic mechanisms of these hereditary cancer subsets is relevant in order the able to discriminate between high- and low-risk groups, to identify novel predisposition loci, and improve targeted cancer control measures and pharmacological therapy. The lessons from hereditary cancer have dual clinical implications related to 
genetic counseling and diagnostics for hereditary cancer and insights into pathways and prognostic markers in CRC in general. Knowledge of familial CRC risks has the potential to impact patient management and subsequent screening and surveillance strategies. There is a need for preventive strategies that can utilize biomarkers in order to stratify patients into appropriate screening or surveillance programs.

\section{References}

1 Heinen CD: Mismatch repair defects and Lynch syndrome: The role of the basic scientist in the battle against cancer. DNA Repair (Amst) 38: 127-134, 2016.

2 Center MM, Jemal A, Smith RA and Ward E: Worldwide variations in colorectal cancer. CA Cancer J Clin 59: 366-378, 2009.

3 Patel SG and Ahnen DJ: Familial colon cancer syndromes: an update of a rapidly evolving field. Curr Gastroenterol Rep 14: 428-438, 2012.

4 Moller P, Seppala T, Bernstein I, Holinski-Feder E, Sala P, Evans DG, Lindblom A, Macrae F, Blanco I, Sijmons R, Jeffries J, Vasen H, Burn J, Nakken S, Hovig E, Rodland EA, Tharmaratnam K, de Vos Tot Nederveen Cappel WH, Hill J, Wijnen J, Green K, Lalloo F, Sunde L, Mints M, Bertario L, Pineda M, Navarro M, Morak M, Renkonen-Sinisalo L, Frayling IM, Plazzer JP, Pylvanainen K, Sampson JR, Capella G, Mecklin JP, Moslein G and Mallorca G: Cancer incidence and survival in Lynch syndrome patients receiving colonoscopic and gynaecological surveillance: first report from the prospective Lynch syndrome database. Gut 2015, doi: 10.1136/gutjnl-2015-309675.

5 Ballester V and Boardman L: Next Generation Multigene Panel Testing: The Next Step for Identification of Hereditary Colorectal Cancer Syndromes? Gastroenterology 149: 526-528, 2015.

6 Lynch HT, Shaw MW, Larsen AL, Magnuson CW and Krush A: Cancer families and multiple primary malignancies - endometrium and colon carcinoma. J Amer Med Assoc 196: 576, 1966.

7 Boland CR and Troncale FJ: Familial colonic-cancer without antecedent polyposis. Ann Intern Med 100: 700-701, 1984.

8 Sjursen W, Haukanes BI, Grindedal EM, Aarset H, Stormorken A, Engebretsen LF, Jonsrud C, Bjornevoll I andresen PA, Ariansen S, Lavik LAS, Gilde B, Bowitz-Lothe IM, Maehle L and Moller P: Current clinical criteria for Lynch syndrome are not sensitive enough to identify MSH6 mutation carriers. Journal of Medical Genetics 47: 579-585, 2010.

9 Tiwari AK, Roy HK and Lynch HT: Lynch syndrome in the 21st century: clinical perspectives. Qjm-Int J Med 109: 151-158, 2016.

10 Vasen HFA and Wijnen J: Clinical implications of genetic testing of hereditary nonpolyposis colorectal cancer. Cytogenet Cell Genet 86: 136-139, 1999.

11 Umar A and Srivastava S: The promise of biomarkers in colorectal cancer detection. Dis Markers 20: 87-96, 2004.

12 Vasen HF and Muller H: DNA studies in families with hereditary forms of cancer. Ned Tijdschr Geneeskd 135: 1620-1623, 1991.

13 Rodriguez-Bigas MA, Boland CR, Hamilton SR, Henson DE, Jass JR, Khan PM, Lynch H, Perucho M, Smyrk T, Sobin L and Srivastava S: A National Cancer Institute Workshop on Hereditary Nonpolyposis Colorectal Cancer Syndrome: meeting highlights and Bethesda guidelines. J Natl Cancer Inst 3: 1758-1762, 1997.
14 Lindor NM, Rabe K, Petersen GM, Haile R, Casey G, Baron J, Gallinger S, Bapat B, Aronson M, Hopper J, Jass J, LeMarchand L, Grove J, Potter J, Newcomb P, Terdiman JP, Conrad P, Moslein G, Goldberg R, Ziogas A, Anton-Culver H, de Andrade M, Siegmund K, Thibodeau SN, Boardman LA and Seminara D: Lower cancer incidence in Amsterdam-I criteria families without mismatch repair deficiency - Familial colorectal cancer type X. Jama-J Am Med Assoc 293: 1979-1985, 2005.

15 Abdel-Rahman WM, Ollikainen M, Kariola R, Jarvinen HJ, Mecklin JP, Nystrom-Lahti M, Knuutila S and Peltomaki P: Comprehensive characterization of HNPCC-related colorectal cancers reveals striking molecular features in families with no germline mismatch repair gene mutations. Oncogene 24: 1542$1551,2005$.

16 Katz LH, Burton-Chase AM, Advani S, Fellman B, Polivka KM, Yuan Y, Lynch PM and Peterson SK: Screening adherence and cancer risk perceptions in colorectal cancer survivors with Lynch-like syndrome. Clin Genet 89: 392-398, 2016.

17 Carethers JM and Stoffel EM: Lynch syndrome and Lynch syndrome mimics: The growing complex landscape of hereditary colon cancer. World J Gastroenterol 21: 9253-9261, 2015.

18 Hampel H, Frankel WL, Martin E, Arnold M, Khanduja K, Kuebler P, Nakagawa H, Sotamaa K, Prior TW, Westman J, Panescu J, Fix D, Lockman J, Comeras I and de la Chapelle A: Screening for the Lynch syndrome (hereditary nonpolyposis colorectal cancer). N Engl J Med 352: 1851-1860, 2005.

19 Hampel H, Frankel W, Panescu J, Lockman J, Sotamaa K, Fix D, Comeras I, La Jeunesse J, Nakagawa H, Westman JA, Prior TW, Clendenning M, Penzone P, Lombardi J, Dunn P, Cohn DE, Copeland L, Eaton L, Fowler J, Lewandowski G, Vaccarello L, Bell J, Reid G and de la Chapelle A: Screening for Lynch syndrome (hereditary nonpolyposis colorectal cancer) among endometrial cancer patients. Cancer Res 66: 7810-7817, 2006.

20 Rubenstein JH, Enns R, Heidelbaugh J, Barkun A and Clinical Guidelines C: American Gastroenterological Association Institute guideline on the diagnosis and management of Lynch syndrome. Gastroenterology 149: 777-782, 2015.

21 Kobayashi H, Ohno S, Sasaki Y and Matsuura M: Hereditary breast and ovarian cancer susceptibility genes. Oncol Rep 30: 1019-1029, 2013.

22 Niessen RC, Hofstra RMW, Westers H, Ligtenberg MJL, Kooi K, Jager POJ, de Groote ML, Dijkhuizen T, Olderode-Berends MJW, Hollema H, Kleibeuker JH and Sijmons RH: Germline Hypermethylation of MLH1 and EPCAM deletions are a frequent cause of Lynch syndrome. Gene Chromosome Canc 48: 737-744, 2009.

23 Ligtenberg MJL, Kuiper RP, Chan TL, Goossens M, Hebeda KM, Voorendt M, Lee TYH, Bodmer D, Hoenselaar E, Hendriks-Cornelissen SJB, Tsui WY, Kong CK, Brunner HG, van Kessel AG, Yuen ST, van Krieken JHJM, Leung SY and Hoogerbrugge $\mathrm{N}$ : Heritable somatic methylation and inactivation of MSH2 in families with Lynch syndrome due to deletion of the 3 ' exons of TACSTD1. Nat Genet 41: 112-117, 2009.

24 Kovacs ME, Papp J, Szentirmay Z, Otto S and Olah E: Deletions removing the last exon of TACSTD1 constitute a distinct class of mutations predisposing to Lynch syndrome. Human Mutation 30: 197-203, 2009. 
25 Guarinos C, Castillejo A, Barbera VM, Perez-Carbonell L, Sanchez-Heras AB, Segura A, Guillen-Ponce C, Martinez-Canto A, Castillejo MI, Egoavil CM, Jover R, Paya A, Alenda C and Soto JL: EPCAM Germline deletions as causes of Lynch syndrome in Spanish patients. J Mol Diagn 12: 765-770, 2010.

26 Eguchi H, Kumamoto K, Suzuki O, Kohda M, Tada Y, Okazaki $\mathrm{Y}$, and Ishida $\mathrm{H}$ : Identification of a Japanese Lynch syndrome patient with large deletion in the 3 ' region of the EPCAM gene. Jpn J Clin Oncol 46: 178-184, 2016.

27 Thompson BA, Spurdle AB, Plazzer JP, Greenblatt MS, Akagi K, Al-Mulla F, Bapat B, Bernstein I, Capella G, den Dunnen JT, du Sart D, Fabre A, Farrell MP, Farrington SM, Frayling IM, Frebourg T, Goldgar DE, Heinen CD, Holinski-Feder E, Kohonen-Corish M, Robinson KL, Leung SY, Martins A, Moller P, Morak M, Nystrom M, Peltomaki P, Pineda M, Qi M, Ramesar R, Rasmussen LJ, Royer-Pokora B, Scott RJ, Sijmons R, Tavtigian SV, Tops CM, Weber T, Wijnen J, Woods MO, Macrae F, Genuardi M and InSiGht: Application of a 5-tiered scheme for standardized classification of 2,360 unique mismatch repair gene variants in the InSiGHT locus-specific database. Nat Genet 46: 107-115, 2014.

28 Buchanan DD, Tan YY, Walsh MD, Clendenning M, Metcalf AM, Ferguson K, Arnold ST, Thompson BA, Lose FA, Parsons MT, Walters RJ, Pearson SA, Cummings M, Oehler MK, Blomfield PB, Quinn MA, Kirk JA, Stewart CJ, Obermair A, Young JP, Webb PM and Spurdle AB: Tumor mismatch repair immunohistochemistry and DNA $M L H 1$ methylation testing of patients with endometrial cancer diagnosed at age younger than 60 years optimizes triage for population-level germline mismatch repair gene mutation testing. J Clin Oncol 32: 90-100, 2014

29 Mas-Moya J, Dudley B, Brand RE, Thull D, Bahary N, Nikiforova MN and Pai RK: Clinicopathological comparison of colorectal and endometrial carcinomas in patients with LynchLike syndrome versus patients with Lynch syndrome. Hum Pathol 46: 1616-1625, 2015.

30 Liu Q, Hesson LB, Nunez AC, Packham D, Williams R, Ward RL and Sloane MA: A cryptic paracentric inversion of $M S H 2$ exons 2-6 causes Lynch syndrome. Carcinogenesis 37: 10-17, 2016.

31 Rhees J, Arnold M and Boland CR: Inversion of exons 1-7 of the $\mathrm{MSH} 2$ gene is a frequent cause of unexplained Lynch syndrome in one local population. Fam Cancer 13: 219-225, 2014.

32 Mensenkamp AR, Vogelaar IP, van Zelst-Stams WAG, Goossens M, Ouchene H, Hendriks-Cornelissen SJB, Kwint MP, Hoogerbrugge N, Nagtegaal ID and Ligtenberg MJL: Somatic Mutations in $M L H 1$ and $M S H 2$ are a frequent cause of mismatch-repair deficiency in Lynch syndrome-like tumors. Gastroenterology 146: 643-646, 2014.

33 Haraldsdottir S, Hampel H, Tomsic J, Frankel WL, Pearlman R, de la Chapelle A and Pritchard CC: Colon and endometrial cancers with mismatch repair deficiency can arise from somatic, rather than germline, mutations. Gastroenterology 147: 13081316, 2014.

34 Rodriguez-Soler M, Perez-Carbonell L, Guarinos C, Zapater P, Castillejo A, Barbera VM, Juarez M, Bessa X, Xicola RM, Clofent J, Bujanda L, Balaguer F, Rene JM, de-Castro L, MarinGabriel JC, Lanas A, Cubiella J, Nicolas-Perez D, BreaFernandez A, Castellvi-Bel S, Alenda C, Ruiz-Ponte C, Carracedo A, Castells A andreu M, Llor X, Soto JL, Paya A and Jover R: Risk of cancer in cases of suspected Lynch syndrome without germline mutation. Gastroenterology 144: 926-932, 2013.
35 Kravochuck SE and Church JM: Hereditary non-polyposis colorectal cancer/Lynch syndrome in three dimensions. ANZ J Surg 2016. doi: 10.1111/ans.13483

36 Yamaguchi T, Furukawa Y, Nakamura Y, Matsubara N, Ishikawa H, Arai M, Tomita N, Tamura K, Sugano K, Ishioka C, Yoshida T, Moriya Y, Ishida H, Watanabe T, Sugihara K and Rectum JSCC: Comparison of clinical features between suspected familial colorectal cancer type $\mathrm{X}$ and Lynch syndrome in Japanese patients with colorectal cancer: a cross-sectional study conducted by the Japanese Society for Cancer of the Colon and Rectum. Jpn J Clin Oncol 45: 153-159, 2015.

37 Francisco I, Albuquerque C, Lage P, Belo H, Vitoriano I, Filipe B, Claro I, Ferreira S, Rodrigues P, Chaves P, Leitao CN and Pereira AD: Familial colorectal cancer type $\mathrm{X}$ syndrome: two distinct molecular entities? Fam Cancer 10: 623-631, 2011.

38 Therkildsen C, Jonsson G, Dominguez-Valentin M, Nissen A, Rambech E, Halvarsson B, Bernstein I, Borg A and Nilbert M: Gain of chromosomal region 20q and loss of 18 discriminates between Lynch syndrome and familial colorectal cancer. Eur J Cancer 49: 1226-1235, 2013.

39 Dominguez-Valentin M, Therkildsen C, Veerla S, Jonsson M, Bernstein I, Borg A, and Nilbert M: Distinct gene expression signatures in Lynch syndrome and familial colorectal cancer type X. Plos One 12: e 71755, 2013.

40 Dominguez-Valentin M, Therkildsen C, Da Silva S and Nilbert M: Familial colorectal cancer type $\mathrm{X}$ : genetic profiles and phenotypic features. Mod Pathol 28: 30-36, 2015.

41 Joensuu EI, Abdel-Rahman WM, Ollikainen M, Ruosaari S, Knuutila $S$ and Peltomaki P: Epigenetic signatures of familial cancer are characteristic of tumor type and family category. Cancer Res 68: 4597-4605, 2008.

42 Goel A, Xicola RM, Nguyen TP, Doyle BJ, Sohn VR, Bandipalliam P, Rozek LS, Reyes J, Cordero C, Balaguer F, Castells A, Jover R andreu M, Syngal S, Boland CR and Llor X: Aberrant DNA methylation in hereditary nonpolyposis colorectal cancer without mismatch repair deficiency. Gastroenterology 138: 1854-U1857, 2010.

43 Sanchez-Tome E, Rivera B, Perea J, Pita G, Rueda D, Mercadillo F, Canal A, Gonzalez-Neira A, Benitez J and Urioste M: Genome-wide linkage analysis and tumoral characterization reveal heterogeneity in familial colorectal cancer type X. J Gastroenterol 50: 657-666, 2015.

44 Jover R and Castells A: Molecular information defines a new entity of hereditary colorectal cancer. Gastroenterology 134 : 888-889; discussion 889-890, 2008.

45 Valle L, Perea J, Carbonell P, Fernandez V, Dotor AM, Benitez $\mathrm{J}$ and Urioste M: Clinicopathologic and pedigree differences in amsterdam I-positive hereditary nonpolyposis colorectal cancer families according to tumor microsatellite instability status. J Clin Oncol 25: 781-786, 2007.

46 Llor X, Pons E, Xicola RM, Castells A, Alenda C, Pinol V, Andreu M, Castellvi-Bel S, Paya A, Jover R, Bessa X, Giros A, Roca A, Gassull MA and Grp GO: Differential features of colorectal cancers fulfilling Amsterdam criteria without involvement of the mutator pathway. Clin Cancer Res 11: 73047310, 2005

47 Mueller-Koch Y, Vogelsang H, Kopp R, Lohse P, Keller G, Aust D, Muders M, Gross M, Daum J, Schiemann U, Grabowski M, Scholz M, Kerker B, Becker I, Henke G and Holinski-Feder E: Hereditary non-polyposis colorectal cancer: clinical and 
molecular evidence for a new entity of hereditary colorectal cancer. Gut 54: 1733-1740, 2005.

48 de la Chapelle A and Hampel H: Clinical Relevance of Microsatellite Instability in Colorectal Cancer. J Clin Oncol 28: 3380-3387, 2010.

49 Boland CR and Goel A: Microsatellite instability in colorectal cancer. Gastroenterology 138: 2073-U2087, 2010.

50 Jenkins MA, Southey MC, Giles GG and Hopper JL: Rationale for and approach to, studying modifiers of risk in persons with a genetic predisposition to colorectal cancer. Curr Oncol Rep 9: 202-207, 2007.

51 Lindor NM: Familial colorectal cancer type X: the other half of hereditary nonpolyposis colon cancer syndrome. Surg Oncol Clin N Am 18: 637-645, 2009.

52 Castells A, Castellvi-Bel S and Balaguer F: Concepts in familial colorectal cancer: here do we stand and what is the future? Gastroenterology 137: 404-409, 2009.

53 Lynch HT, Lynch JF and Attard TA: Diagnosis and management of hereditary colorectal cancer syndromes: Lynch syndrome as a model. Can Med Assoc J 181: 273-280, 2009.

54 Balmana J, Castells A, Cervantes A and Grp EGW: Familial colorectal cancer risk: ESMO Clinical Practice Guidelines. Annals of Oncology 21: v78-v81, 2010.

55. Balmana J, Balaguer F, Cervantes A, Arnold D and Grp EGW: Familial risk-colorectal cancer: ESMO Clinical Practice Guidelines. Ann Oncol 24: 73-80, 2013.
56 Stoffel EM, Mangu PB, Gruber SB, Hamilton SR, Kalady MF, Lau MW, Lu KH, Roach N, Limburg PJ, American Society of Clinical $\mathrm{O}$ and European Society of Clinical O: Hereditary colorectal cancer syndromes: American Society of Clinical Oncology Clinical Practice Guideline endorsement of the familial risk-colorectal cancer: European Society for Medical Oncology Clinical Practice Guidelines. J Clin Oncol 33: 209-217, 2015.

57 Rothwell PM, Fowkes FG, Belch JF, Ogawa H, Warlow CP and Meade TW: Effect of daily aspirin on long-term risk of death due to cancer: analysis of individual patient data from randomised trials. Lancet 377: 31-41, 2011.

58 Burn J, Gerdes AM, Macrae F, Mecklin JP, Moeslein G, Olschwang S, Eccles D, Evans DG, Maher ER, Bertario L, Bisgaard ML, Dunlop MG, Ho JW, Hodgson SV, Lindblom A, Lubinski J, Morrison PJ, Murday V, Ramesar R, Side L, Scott RJ, Thomas HJ, Vasen HF, Barker G, Crawford G, Elliott F, Movahedi M, Pylvanainen K, Wijnen JT, Fodde R, Lynch HT, Mathers JC, Bishop DT and Investigators C: Long-term effect of aspirin on cancer risk in carriers of hereditary colorectal cancer: an analysis from the CAPP2 randomised controlled trial. Lancet 378: 2081-2087, 2011.

Received July 1, 2016

Revised July 14, 2016

Accepted July 18, 2016 